\title{
Purification efficiency of eight aquatic plant species in an artificial floating island system in relation to extracellular enzyme activity and microbial community
}

\author{
Lei $\mathrm{Li}^{1}$, You Feng ${ }^{1}$, Jinye $\mathrm{Li}^{1}$, Qing $\mathrm{Li}^{1}$, Ting Liu ${ }^{1}$, Qingfeng Chen ${ }^{1,2^{\dagger}}$ \\ ${ }^{1}$ Qilu University of Technology (Shandong Academy of Sciences), Shandong Analysis and Test Center, Key Laboratory for Applied Technology of \\ Sophisticated Analytical Instrument of Shandong Province, Jinan 250014, China \\ ${ }^{2}$ College of Geography and Environment, Shandong Normal University, Jinan 250014, Shandong, China
}

\begin{abstract}
The floating island system exploits the combination of aquatic plants, microorganisms, and extracellular enzymes to purify wastewater. We investigated the purification efficiency of eight aquatic plant species cultured in wastewater. The relationships of plant purification capacity with extracellular enzyme activity and microbial community were analyzed to explore the crucial factors that affect the plant purification capacity and the mechanism of pollutants removal in different plant systems. Three plant species, namely Oenanthe javanica, Thalia dealbata, and lris pseudacorus, were most effective for purification of ammonium-nitrogen $\left(\mathrm{NH}_{4}{ }^{+}-\mathrm{N}\right)$, total phosphate (TP), and chemical oxygen demand (COD) with maximum efficiencies of $76.09,85.87$, and $89.10 \%$, respectively. Urease, alkaline phosphatase (AP), and $\beta$-glucosidase activities were significantly and positively correlated with root system development $(P<0.05)$. Activities of urease and $\mathrm{AP}$ were positively correlated with $\mathrm{NH}_{4}{ }^{+}-\mathrm{N}$ and TP removal, respectively. The magnitude of urease and AP activity was generally consistent with the plant's capacity to remove $\mathrm{NH}_{4}{ }^{+}-\mathrm{N}^{\prime}$ and TP. $\beta$-Glucosidase activity and COD removal were not significantly correlated. The dominant microbial phylum in each species treatment was Proteobacteria. Alphaproteobacteria and Bacteroidia showed $>1 \%$ relative abundance and greater involvement in degradation of pollutants in the experimental system.
\end{abstract}

Keywords: Aquatic plant, Extracellular enzyme, Floating island, Microorganisms, Purification efficiency, Wastewater

\section{Introduction}

An artificial floating island is an ecological restoration technology aimed at creating sustainable ecosystems conducive to enhancement or restoration of biodiversity [1]. The approach has proved to be remarkably effective in the treatment of polluted rivers, lakes, and reservoirs [2]. The strategy is advantageous in being space efficient compared with the spatial requirements of an artificial wetland [3]. Artificial floating island systems remove pollutants through absorption by aquatic plant roots, and mitigate nitrogen and phosphorus enrichment in the water by means of microbial degradation [4-6].

The roots of aquatic plants provide habitat for microorganisms to grow on the surface of plant stems and roots, which can enhance the removal of organic matter [7]. Hundreds of plants are now available for artificial floating islands, from the original crops, to aquatic plants with well-developed root systems such as Phragmites australis, Cyperus involucratus Rottboll and Lolium, to landscape flowering plants such as Acorus calamus, Canna indica, Thalia dealbataand other flowering plant. Comparing the nitrogen and phosphorus removal of the plants in spring and autumn, the nitrogen and phosphorus removal of Myriophyllum spicatum and Hydrocotyle verticillata were significantly better in spring than in autumn [8]. Floating islands with different plant combinations were more effective in removing total phosphorus than those planted with a single plant. Some plants can actually degrade the toxic chemical polyvinyl chloride [9]. Artificial floating islands (GAFI) equipped with oriental balsam, durgis and knotweed as purification plants with the addition of solar-powered aeration device. GAFI was effective in inhibiting algal growth and increasing
This is an Open Access article distributed under the terms of the Creative Commons Attribution Non-Commercial License (http://creativecommons.org/licenses/by-nc/3.0/) which permits unrestricted non-commercial use, distribution, and reproduction in any medium, provided the original work is properly cited.

Copyright (C) 2022 Korean Society of Environmental Engineers
Received September 13, 2021 Accepted November 26, 2021

${ }^{\dagger}$ Corresponding author

E-mail: chensdcn@163.com

Tel: +15053170989 Fax: +82964889

ORCID: 0000-0002-4084-2347 
dissolved oxygen [10]. In addition, the area planted with floating island plants is significantly smaller than that of wetland plants for the same purification effect [11, 12]. In addition to improving water quality, artificial floating islands can as well be used for landscape enhancement, habitat and riparian zone protection [13].

Many biopolymers, such as proteins, nucleic acids, and polysaccharides, cannot be transported across cell membranes and used directly by microorganisms in wastewater [14]. However, such biopolymers can be used by microorganisms if degraded into simpler compounds or inorganic substances as a result of hydrolysis by extracellular enzymes [15, 16].

The floating island system uses a combination of aquatic plants, microorganisms, and extracellular enzymes for wastewater purification. Extracellular enzymes are synthesized within the cell and subsequently are translocated across the cell membrane; these enzymes are either localized around the cell membrane or diffuse into the environment and function outside the cell. Extracellular enzymes are complex in origin and are synthesized by diverse sources in different ecosystems, including plant roots, phytoplankton, and microorganisms. Such enzymes play important roles in the biogeochemical cycling of carbon, nitrogen, and phosphorus in ecosystems.

From a sustainability point of view, ecological floating island technology can achieve an environmenta-friendly virtuous cycle, ecological restoration, landscape effects and ecological functions. Research on artificial floating island systems has typically focused on improvement of the selected materials and technological innovation, and less frequently on extracellular enzymes, microorganisms, and aquatic plants. In the present study, analyses of microbial diversity and the relationships between extracellular enzyme activities and pollutant removal efficiency, and between plant root growth and extracellular enzyme activities, were conducted to investigate the influence of extracellular enzyme activity and microorganisms on the purification effectiveness of artificial floating islands. The results provide a scientific and theoretical basis for improvement of the purification efficiency of aquatic plants in artificial floating island systems.

\section{Materials and Methods}

\subsection{Experimental Materials}

The experiment was conducted at a greenhouse at the laboratory

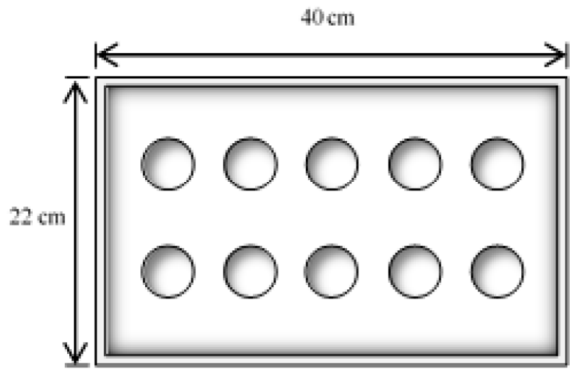

of Shandong Analysis and Test Center. Eight aquatic plant species were selected, comprising Ceratophyllum demersum, Elodea nuttallii, Eichhornia crassipes, Iris pseudacorus, Iris sibirica, Myriophyllum verticillatum, Thalia dealbata and Oenanthe javanica. The plants were incubated under a photoperiod of 14 $\mathrm{h} / 10 \mathrm{~h}$ (light/dark), light intensity $300-330 \mu \mathrm{mol} \cdot \mathrm{m}^{-2} \cdot \mathrm{s}^{-1}$, temperature $\sim 25^{\circ} \mathrm{C}$, and relative humidity $50-70 \%$. Plant seedlings were first cultured for 2 weeks in Hoagland's nutrient solution for acclimation to an aquatic environment and then transferred to the experimental device. A total of 27 miniature floating island devices of size $40 \times 22 \times 15 \mathrm{~cm}$ were established (Fig. 1).

\subsection{Experimental Method}

\subsubsection{Experimental design}

Experimental water samples were collected from the oxidation pond of the wastewater treatment system of a large livestock farm in Linyi, Shandong Province, China (Table S1). Well-grown plants with intact leaves of relatively similar size and biomass were selected for the experiment. The experiment used a total of 27 groups of plants, with 10 plants per group. The total mass of each group was similar. The roots of each plant were rinsed three times with distilled water and then blotted dry with absorbent paper. Ten liters of the prepared wastewater was placed in the miniature floating island devices and the water level was marked. A plastic plate perforated with 10 holes was placed on top of the container, and 10 plants of the same species were secured in place with planting baskets. Three replicate groups for each of plant species were established for each treatment. A simulated floating island lacking plants with the same volume of wastewater was used as the control (CK). Samples of the water were collected at 7 day intervals during the experimental period, that is, at the time points $0,7,14,21$, and $28 \mathrm{~d}$, respectively. Due to the water consumption caused by evaporation, plant transpiration and sampling, it is necessary to replenish the water level with distilled water before sampling. At the end of the experiment, the root weight and length were measured for each plant.

On day 28th, a $500 \mathrm{~mL}$ sample was collected from the water in the vicinity of the root system at a depth of $10 \mathrm{~cm}$ below the water surface. The water samples from the three replicates of each group were mixed thoroughly. Microbial membrane filters were used for extraction to enrich microorganisms on the

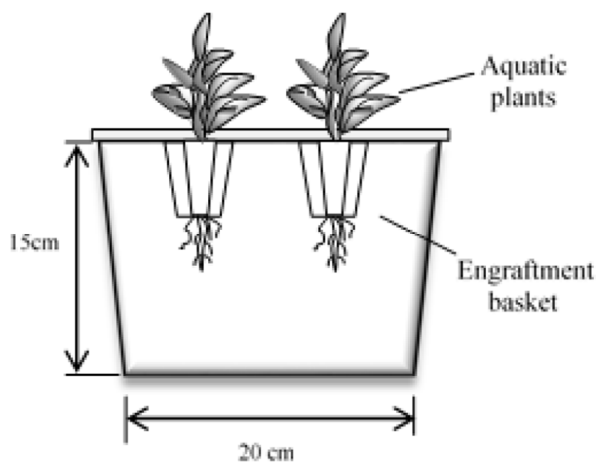

Fig. 1. Schematic diagram of the artificial floating island device used in the study. 
membranes. The filter membranes were immediately stored at $-80^{\circ} \mathrm{C}$ and transported to a gene sequencing company for $16 \mathrm{~S}$ rDNA sequencing.

\subsubsection{DNA extraction and sequencing processing}

DNA extraction kits were applied to extract total DNA. The target segment was $16 \mathrm{~s} \mathrm{~V} 3+\mathrm{V} 4$, the target sequence are CCTAYGG GRBGCASCAG, GGACTACNNGGGTATCTAAT, and the corresponding primers are 341F, 806R. PCR amplification was performed, and the product was purified, quantified, and homogenized to create a sequence library. After the library was qualified, it was sequenced by Illumina HiSeq. The initial sequences were splice filtrated and divided into operational taxonomic units for species annotation and abundance analysis. Diversity indexes in term of Simpson, Chao1, abundance-based coverage estimator (ACE) and Shannon were calculated using Mothur. QIIME was used for representative sequence species annotation. In addition, significant species difference analysis was conducted to explore the differences among samples. Biological function of the microbiota was predicted using PICRUSt (http://picrust.github.com/picrust/).

\subsubsection{Chemical analysis}

The wastewater quality indicators such as ammonium-nitrogen $\left(\mathrm{NH}_{4}{ }^{+}-\mathrm{N}\right)$ concentration, total phosphorus (TP) concentration, and chemical oxygen demand (COD) in the experimental water samples were measured in accordance with the protocols of the State Environmental Protection Administration (SEPA). Urease (URE) activity was determined using the sodium phenate and sodium hypochlorite colorimetric method. The content of $\mathrm{NH}_{4}{ }^{+}-\mathrm{N}$ in 1 $\mathrm{mL}$ of the water sample after $24 \mathrm{~h}$ was determined to express URE activity. Alkaline phosphatase (AP) activity was measured using the disodium phosphate-benzene colorimetric method. The amount of phenol released from $1 \mathrm{~mL}$ of the water sample after $12 \mathrm{~h}$ was measured to express AP activity. The $\beta$-glucosidase $(\beta-G L U)$ activity was determined using the $p$-nitrophenyl colorimetric procedure. The $\beta$-GLU activity was measured as the amount of $p$-nitrophenyl released from $1 \mathrm{~mL}$ of the water sample after $1 \mathrm{~min}$ at $\mathrm{pH} 5.0$ at $37^{\circ} \mathrm{C}$.

\subsubsection{Data analysis}

Using the experimental data, a regression analysis of wastewater concentration and treatment duration was conducted. The regression equation for the pollutant concentration versus time for each group was obtained.

The regression equation of $\mathrm{NH}_{4}{ }^{+}-\mathrm{N}$, TP or COD concentrations with time $(\mathrm{t})$ is shown below:

$$
y=a e^{-b x}(a>0, b>0)
$$

Where: $y$ is the indicator concentration $(\mathrm{mg} / \mathrm{L})$ and $x$ is the time (d). In this equation, the value of $b$ determines the magnitude of $y$ when the value of $a$ is certain, hence the value of $b$ characterizes the removal capacity of each group of pollutants.

Expression of the growth rate of the pollutant metric was calculated with the following formula:

$$
y=\left(C_{28}-C_{0}\right) / C_{0} \times 100 \%
$$

where: $C_{0}$ is the concentration of $\mathrm{NH}_{4}{ }^{+}-\mathrm{N}$, TP, or COD in the wastewater at the beginning of the experiment, and $C_{28}$ is the concentration of $\mathrm{NH}_{4}{ }^{+}-\mathrm{N}$, TP, or COD in the water at the end of the experiment.

The root growth status of plants was expressed as the root quality index (RQ), which represented the degree of root development. The RQ was calculated using the formula:

$$
\mathrm{RQ}=\mathrm{RM} / \mathrm{RL}
$$

Where: RM is the root biomass ( $\mathrm{g}$ ) and RL is the root length (cm). The roots of submerged plants were degraded and contact with water was all biomass; Therefore, the RL of the three submerged plant species (Myriophyllum verticillatum, Elodea nuttallii, and Ceratophyllum demersum) was recorded as 1 .

The experimental data were processed using SPSS 17.0 statistical software and graphs were generated using Origin 2017 software. The Pearson product-moment correlation test was used for calculation of correlation coefficients.

\section{Results}

\subsection{Relationship between Extracellular Enzymes and Pollutant Removal Effectiveness}

The enzymes URE, AP, and $\beta$-GLU are obligate hydrolases [17]. Activity of URE plays an important role in nitrogen mineralization by hydrolyzing urea to ammonia and carbon dioxide. The AP activity is associated with the conversion of organic phosphorus and the release of phosphate from hydrolyzed phospholipids [18]. Activity of $\beta$-GLU catalyzes the hydrolysis of $\beta$-glucosidic bonds in dimeric and oligomeric glucosides and polysaccharides to yield glucose. Therefore, the activities of the three enzymes were compared with the corresponding pollutant concentrations.

\subsubsection{Relationship between URE activity and $\mathrm{NH}_{4}{ }^{+}-\mathrm{N}$ removal rate} During the experimental period, the concentrations of $\mathrm{NH}_{4}{ }^{+}-\mathrm{N}$, $\mathrm{TP}$, and COD in the wastewater of each group were reduced. The ability of the eight plant species to remove the three pollutants from the wastewater differed significantly $(P<0.05)$.

According to the curvilinear regression model for $\mathrm{NH}_{4}{ }^{+}-\mathrm{N}-t$, the Pearson correlation coefficients $(r$ ) for each group ranged from 0.842 to 0.989 and showed a good fit. Based on the value of $b$, the ranking of the species by their ability to degrade $\mathrm{NH}_{4}{ }^{+}-\mathrm{N}$ was (in descending order) lris pseudacorus $>$ Oenanthe javanica $>$ Thalia dealbata $>$ Eichhornia crassipes $>$ Ceratophyllum demersum $>$ Iris sibirica $>$ Myriophyllum verticillatum $>$ Elodea nuttallii. Iris pseudacorus and Oenanthe javanica showed the maximum removal rates of $76.09 \%$ and $75.08 \%$, respectively; Myriophyllum verticillatum and Elodea nuttallii showed the lowest $\mathrm{NH}_{4}{ }^{+}-\mathrm{N}$ removal rates of $69.50 \%$ and $69.31 \%$, respectively. The difference between Elodea nuttallii (with the lowest removal rate) and Iris pseudacorus (with the highest removal rate) was $6.78 \%$, which accounted for $9.76 \%$ of the $\mathrm{NH}_{4}{ }^{+}-\mathrm{N}$ removal by lris pseudacorus.

During the experimental period, URE activity increased in all groups and increased significantly in all treatments with plants compared with the control (Fig. 2(a)). The enzyme activity in 

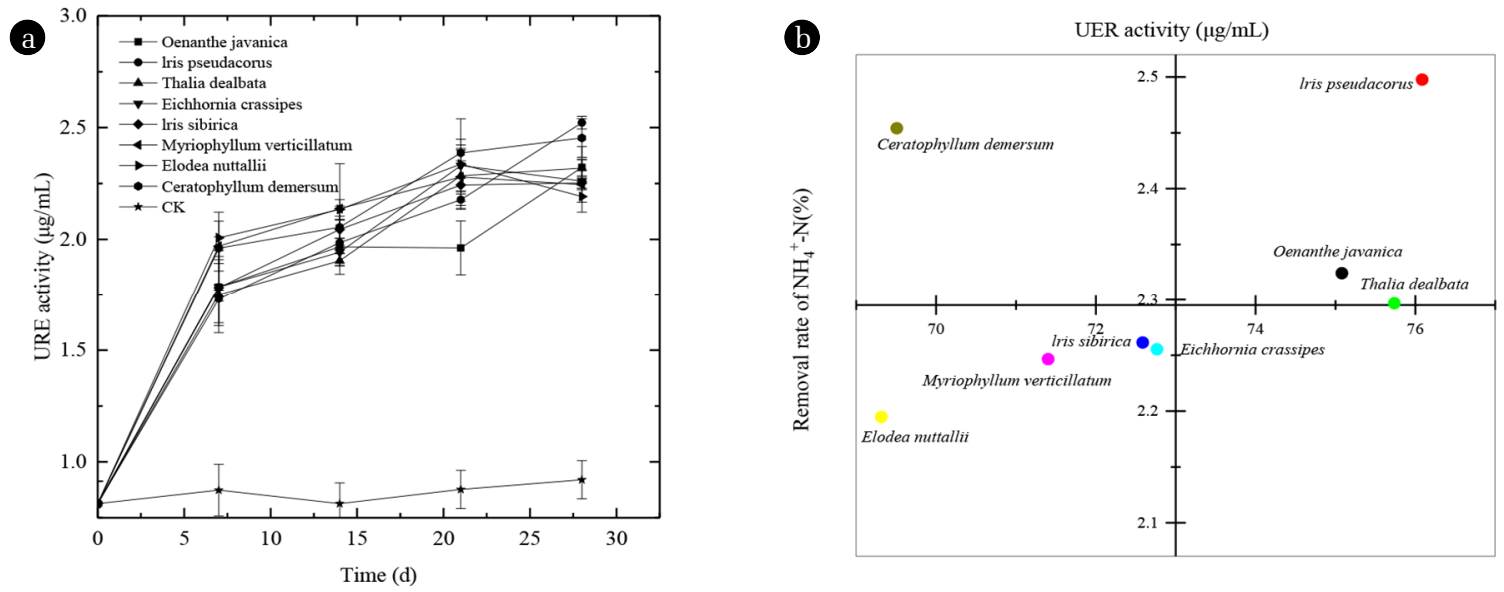

Fig. 2. Variation of URE activity of each aquatic plant and relationship with $\mathrm{NH}_{4}{ }^{+}-\mathrm{N}$ removal rate.

each treatment increased at a more rapid rate in the early stages of incubation and at a lower rate in the later stages of the experimental period. The URE activity in the control (CK) in the absence of plants increased by $13.16 \%$ during the experimental period, indicating that the enzyme at least partially originated from a source other than the plant root system. The relationship between increase in URE activity in the wastewater and the $\mathrm{NH}_{4}{ }^{+}-\mathrm{N}$ removal rate by the different plant species is shown in Fig. 2(b). Among the eight aquatic plant species selected for this experiment, seven showed a positive correlation between $\mathrm{NH}_{4}{ }^{+}-\mathrm{N}$ removal rate and URE activity in wastewater. The $\mathrm{NH}_{4}{ }^{+}-\mathrm{N}$ removal rate was enhanced with the increase in URE activity for each group. In the median scatter plot (Fig. 2(b)), three species were located in the second quadrant, namely (from highest to lowest URE activities) lris pseudacorus, Oenanthe javanica, and Thalia dealbata, which showed URE activities of $2.45,2.32$, and $2.31 \mu \mathrm{g} / \mathrm{mL}$, respectively. The fourth quadrant contained Eichhornia crassipes, Iris sibirica, Myriophyllum verticillatum, and Elodea nuttallii; the latter showed the lowest URE activity of $2.19 \mu \mathrm{g} / \mathrm{mL}$. However, Ceratophyllum demersum did not conform with this general pattern and showed relatively high URE activity $(2.52 \mu \mathrm{g} / \mathrm{mL})$ but a low $\mathrm{NH}_{4}{ }^{+}-\mathrm{N}$ removal rate.

\subsubsection{Relationship between AP activity and TP removal rate}

According to the curvilinear regression model TP- $t$ (Table 1), the Pearson correlation coefficients $(r$ ) for each group ranged from 0.929 to 0.980 and showed a good fit. From the value of $b$, the ranking of the species' ability to degrade TP was (in descending order) Thalia dealbata $>$ Oenanthe javanica $>$ Eichhornia crassipes $>$ Iris pseudacorus $>$ Iris sibirica $>$ Myriophyllum verticillatum $>$ Ceratophyllum demersum $>$ Elodea nuttallii. Thalia dealbata and Oenanthe javanica showed the maximum TP removal rates of $85.87 \%$ and $80.22 \%$, respectively. Ceratophyllum demersum and Elodea nuttallii showed the lowest TP removal rates of $70.84 \%$ and $69.04 \%$, respectively. The difference between Elodea nuttallii (with the lowest removal rate) and Thalia dealbata (with the highest removal rate) was $16.83 \%$, which accounted for $19.60 \%$ of the TP removal by Thalia dealbata.

During the experimental period, the AP activity in all plants treatments groups was higher than that in control group compared
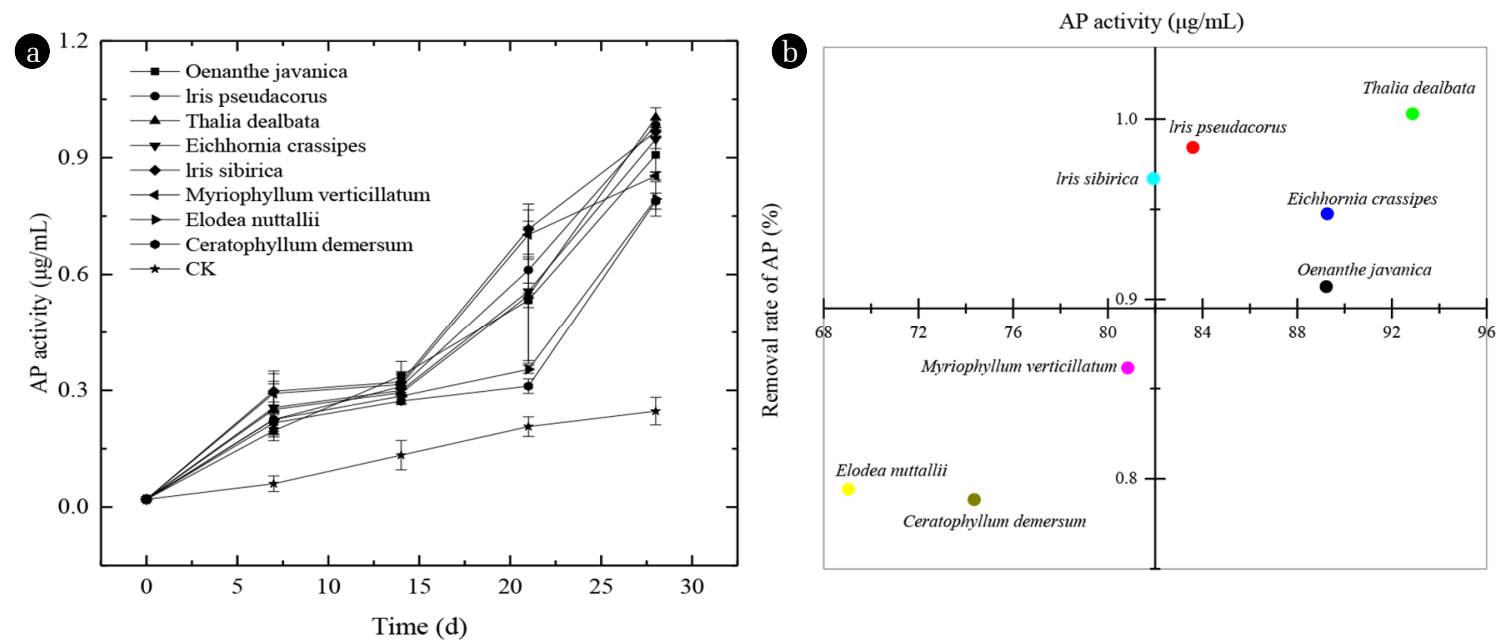

Fig. 3. Variation in AP activity for each aquatic plant and relationship with TP removal rate. 
Table 1. Ammonium-nitrogen $\left(\mathrm{NH}_{4}{ }^{+}-\mathrm{N}\right)$, Total Phosphate (TP) and Chemical Oxygen Demand (COD)-Time ( $t$ ) Regression Equation and Associated Parameters for Each Plant Species

\begin{tabular}{|c|c|c|c|c|}
\hline Pollutants & Plants & The formula & $\boldsymbol{r}$ & $\boldsymbol{b}$ \\
\hline \multirow{8}{*}{$\mathrm{NH}_{4}{ }^{+}-\mathrm{N}$} & Oenanthe javanica & $y=42.893 \mathrm{e}^{-0.0514 x}$ & $0.984^{* *}$ & 0.0514 \\
\hline & Iris pseudacorus & $y=45.407 \mathrm{e}^{-0.0540 x}$ & $0.989^{* *}$ & 0.0540 \\
\hline & Thalia dealbata & $y=37.683 \mathrm{e}^{-0.0496 x}$ & $0.842^{*}$ & 0.0496 \\
\hline & Eichhornia crassipes & $y=44.560 \mathrm{e}^{-0.0487 \mathrm{x}}$ & $0.987^{* *}$ & 0.0487 \\
\hline & Iris sibirica & $y=40.356 \mathrm{e}^{-0.0474 x}$ & $0.963^{* *}$ & 0.0474 \\
\hline & Myriophyllum verticillatum & $y=41.155 \mathrm{e}^{-0.0460 x}$ & $0.966^{* *}$ & 0.0460 \\
\hline & Elodea nuttallii & $y=46.004 \mathrm{e}^{-0.0453 x}$ & $0.970^{* *}$ & 0.0453 \\
\hline & Ceratophyllum demersum & $y=47.038 \mathrm{e}^{-0.0475 \mathrm{x}}$ & $0.870^{*}$ & 0.0475 \\
\hline \multirow{8}{*}{ TP } & Oenanthe javanica & $y=19.056 \mathrm{e}^{-0.0771 x}$ & $0.979^{* *}$ & 0.0771 \\
\hline & lris pseudacorus & $y=19.630 \mathrm{e}^{-0.0621 x}$ & $0.969^{* *}$ & 0.0621 \\
\hline & Thalia dealbata & $y=22.958 \mathrm{e}^{-0.0879 x}$ & $0.929^{* *}$ & 0.0879 \\
\hline & Eichhornia crassipes & $y=18.881 \mathrm{e}^{-0.0769 x}$ & $0.980^{* *}$ & 0.0769 \\
\hline & Iris sibirica & $y=20.161 \mathrm{e}^{-0.0607 x}$ & $0.972^{* *}$ & 0.0607 \\
\hline & Myriophyllum verticillatum & $y=20.636 \mathrm{e}^{-0.0591 x}$ & $0.965^{* *}$ & 0.0591 \\
\hline & Elodea nuttallii & $y=18.523 \mathrm{e}^{-0.0472 x}$ & $0.975^{* *}$ & 0.0472 \\
\hline & Ceratophyllum demersum & $y=19.519 \mathrm{e}^{-0.0479 x}$ & $0.967^{* *}$ & 0.0479 \\
\hline \multirow{8}{*}{ COD } & Oenanthe javanica & $y=208.637 \mathrm{e}^{-0.0948 x}$ & $0.930^{* *}$ & 0.0948 \\
\hline & Iris pseudacorus & $y=240.870 \mathrm{e}^{-0.0825 x}$ & $0.963^{* *}$ & 0.0825 \\
\hline & Thalia dealbata & $y=230.551 \mathrm{e}^{-0.0864 x}$ & $0.943^{* *}$ & 0.0864 \\
\hline & Eichhornia crassipes & $y=244.810 \mathrm{e}^{-0.0774 x}$ & $0.971^{* *}$ & 0.0774 \\
\hline & Iris sibirica & $y=219.349 e^{-0.0912 x}$ & $0.928^{* *}$ & 0.0912 \\
\hline & Myriophyllum verticillatum & $y=221.676 \mathrm{e}^{-0.0895 x}$ & $0.929^{* *}$ & 0.0895 \\
\hline & Elodea nuttallii & $y=229.508 \mathrm{e}^{-0.0814 x}$ & $0.956^{* *}$ & 0.0814 \\
\hline & Ceratophyllum demersum & $y=236.034 \mathrm{e}^{-0.0770 x}$ & $0.969^{* *}$ & 0.0770 \\
\hline
\end{tabular}

", significant at the $P<0.05$ level; ${ }^{* *}$, significant at the $P<0.01$ level

with the control (Fig. 3(a)). The AP activity was highest in the Thalia dealbata treatment, which was 12 -fold higher than that of the control (CK). The relationship between the increase in AP activity and TP removal rate during the experimental period for each plant species is shown in Fig. 3(b). Four species were located in the second quadrant, namely (from highest to lowest AP activities) Thalia dealbata, Iris pseudacorus, Eichhornia crassipes, and Oenanthe javanica, with AP activities of 1.00, 0.98, 0.94, and $0.90 \mu \mathrm{g} / \mathrm{mL}$, respectively. Elodea nuttallii and Ceratophyllum demersum showed the weakest AP activities of 0.79 and $0.78 \mu \mathrm{g} / \mathrm{mL}$, respectively.

3.1.3. Relationship between $\beta-G L U$ activity and COD removal rate According to the curvilinear regression model COD- $t$ (Table 1), the Pearson correlation coefficients $(r$ ) for each group ranged from 0.928 to 0.969 and showed a good fit. From the value of $b$, the ranking of the species' ability to degrade COD was (in descending order) Oenanthe javanica > Iris sibirica $>$ Myriophyllum verticillatum $>$ Thalia dealbata $>$ Iris pseudacorus $>$ Elodea nuttallii $>$ Eichhornia crassipes $>$ Ceratophyllum demersum. Oenanthe javanica and lris sibirica showed the maximum COD removal rates of 89.10 and $87.88 \%$, respectively. Ceratophyllum demersum and Oenanthe javanica showed the lowest COD removal rates of 79.65 and $80.05 \%$, respectively. The difference between Ceratophyllum demersum (with the lowest removal rate) and
Oenanthe javanica (with the highest removal rate) was $9.45 \%$, which accounted for $10.60 \%$ of the COD removal of Oenanthe javanica.

During the experimental period, the activity of $\beta$-GLU in all plant treatment groups was higher than that in control group (Fig. 4(a)). The highest $\beta$-GLU activity of Iris pseudacorus was as high as $1.12 \mathrm{nmol} / \mathrm{mL}$. The $\beta$-GLU activity in the control (CK) increased by $91.67 \%$. The relationship between $\beta-G L U$ activity and COD removal rate for each plant species is shown in Fig. 4(b). The relationship between COD removal rate and $\beta$-GLU activity was not significant among the eight plant species and no significant correlation between the removal efficiency of COD and $\beta-G L U$ activity in each plant species was observed.

\subsection{Correlation of $\mathrm{RQ}$ and Extracellular Enzyme Activities}

Correlation analysis revealed that extracellular enzyme activities in each treatment were positively correlated with the RQ of each plant species. The URE activity was significantly and positively correlated with the RQ of Oenanthe javanica, Eichhornia crassipes, Elodea nuttallii, and Ceratophyllum demersum, and was highly significantly correlated with the RQ of Thalia dealbata, Eichhornia crassipes, and Myriophyllum verticillatum. The AP activity was highly significantly and positively correlated with the RQ of Oenanthe javanica, Iris pseudacorus, Eichhornia crassipes, Elodea 

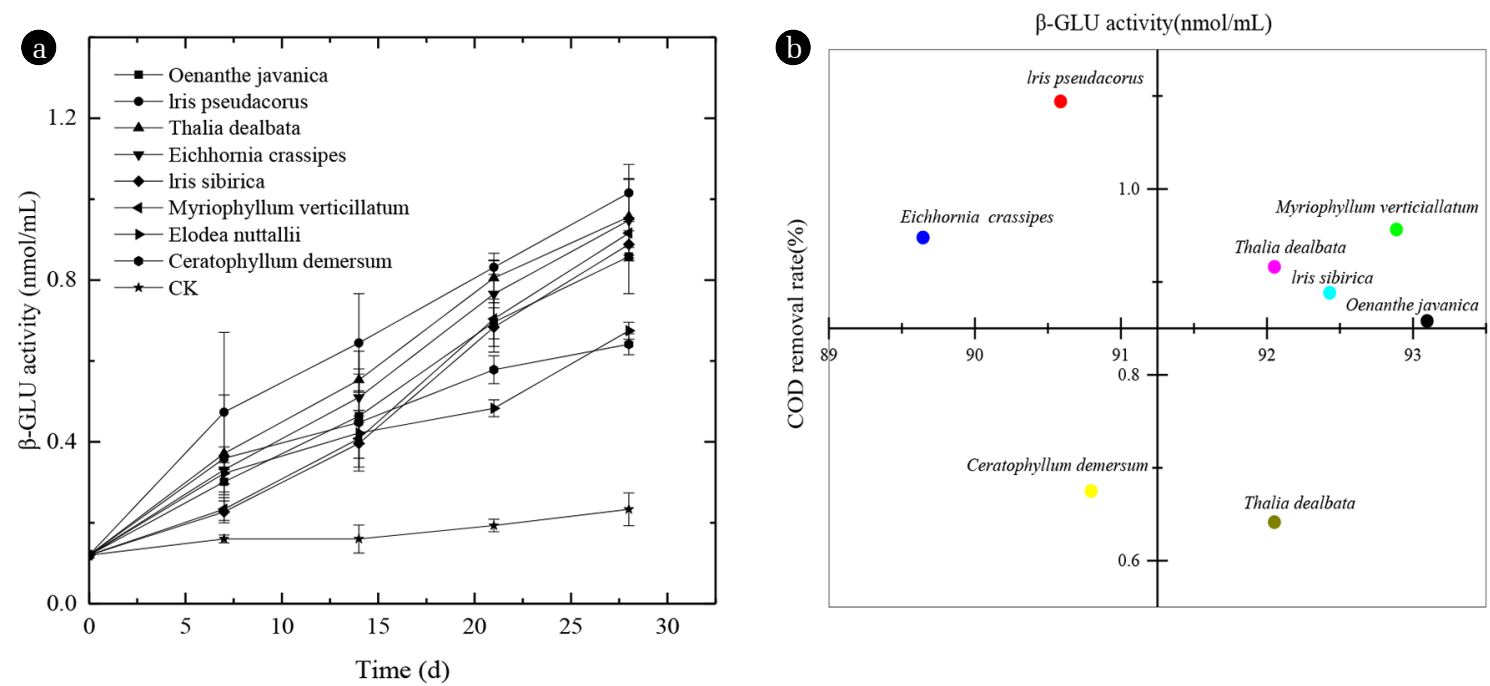

Fig. 4. Variation in $\beta-G L U$ activity for each aquatic plant species and relationship with COD removal rate.

Table 2. Relationship of Extracellular Enzyme Activity and Root Quality Index (RQ) for Each Group of Samples

\begin{tabular}{lcccccccc}
\hline & $\begin{array}{c}\text { Oenanthe } \\
\text { javanica }\end{array}$ & $\begin{array}{c}\text { Iris } \\
\text { pseudacorus }\end{array}$ & $\begin{array}{c}\text { Thalia } \\
\text { dealbata }\end{array}$ & $\begin{array}{c}\text { Eichhornia } \\
\text { crassipes }\end{array}$ & Iris sibirica & $\begin{array}{c}\text { Myriophyllum } \\
\text { verticillatum }\end{array}$ & $\begin{array}{c}\text { Elodea } \\
\text { nuttallii }\end{array}$ & $\begin{array}{c}\text { Ceratophyllu } \\
\text { m demersum }\end{array}$ \\
\hline URE & $0.887^{*}$ & 0.798 & $0.961^{* *}$ & $0.950^{* *}$ & $0.889^{*}$ & $0.984^{* *}$ & $0.870^{*}$ & $0.846^{*}$ \\
AP & $0.987^{* *}$ & $0.977^{* *}$ & $0.889^{*}$ & $0.876^{*}$ & $0.952^{* *}$ & $0.896^{*}$ & $0.923^{* *}$ & $0.865^{*}$ \\
B-GLU & $0.984^{* *}$ & $0.966^{* *}$ & $0.954^{* *}$ & $0.965^{* *}$ & $0.976^{* *}$ & $0.865^{*}$ & $0.891^{* *}$ & $0.914^{* *}$ \\
\hline
\end{tabular}

nuttallii, and significantly and positively correlated with RQ of Thalia dealbata, Eichhornia crassipes, Myriophyllum verticillatum, and Ceratophyllum demersum. The $\beta$-GLU activity was highly significantly and positively correlated with RQ for all plant species. Therefore, the development of the root system of each plant species had a significant effect on the relationship with URE, AP, and $\beta$-GLU activities (Table 2).

\subsection{Microbial Alpha-diversity Index and Species Composition Structure}

In this study, data for microorganisms detected in water samples on day 28th of incubation were used to calculate the alpha-diversity index at the 97\% similarity level (Table S2). The Shannon and Simpson indices are influenced by the abundance and evenness of species in the sample community. Thus, for the same species abundance, the greater the evenness of the species in the community, the greater the diversity of the community. The Chao1 and Ace indices reflect the number of species in the community. The Myriophyllum verticillatum samples showed the highest alpha-diversity and number of species, followed by Thalia dealbata and Ceratophyllum demersum (Table S2). The species diversity and number of species were low in the Oenanthe javanica, Iris pseudacorus, and Elodea nuttallii samples. The lris sibirica samples showed the lowest species diversity but not the lowest number of species, which indicated that one or more microorganisms constituted a large proportion of the microbiota in this treatment.

This study annotated the species of each sample, classified and sorted out the specific bacterial community structure of each sample. Certain differences in species composition structure at the phylum and class levels were observed among the samples (Fig. 5). Only the first six and the first 10 taxa are shown for the phylum and class levels, respectively. At the phylum level, most microorganisms in the samples belonged to the Proteobacteria. Bacteroidetes showed relative abundance greater than $1 \%$ in all samples. In addition, the relative abundance of Actinobacteria was greater than $1 \%$ in samples for all plant species except Eichhornia crassipes (Fig. 5(a)). At the class level, the samples for Eichhornia crassipes, Iris sibirica, Myriophyllum verticillatum, and Ceratophyllum demersum contained a high abundance of Gammaproteobacteria, the samples for lris pseudacorus and Thalia dealbata contained a high abundance of Alphaproteobacteria, and the samples for Oenanthe javanica and Elodea nuttallii contained a high abundance of Bacteroidia. In all cases, these classes showed greater than $10 \%$ relative abundance. The relative abundance of Campylobacteria was also reached $4.8 \%$ in Elodea nuttallii samples (Fig. 5(b)).

Functional gene composition in the samples was predicted by using gene function prediction software PICRUSt and 16S sequence ,KEGG analysis showed no significant differences in metabolic pathways with higher abundance among the 12 samples $(\mathrm{P}<$ 0.05). The metabolic pathways were associated with basal transcription factors. The KEGG pathway analysis predicted the up-regulation of five pathways (basal transcription factors, proteasome, betalain biosynthesis, mRNA surveillance pathway, and vasopressin-regulated water reabsorption) and down-regulation of 10 pathways (e.g., phosphonate and phosphinate metabolism, Staphylococcus aureus infection, and chlorocyclohexane and chlorobenzene degradation). In addition, metabolism of xenobiotics by 

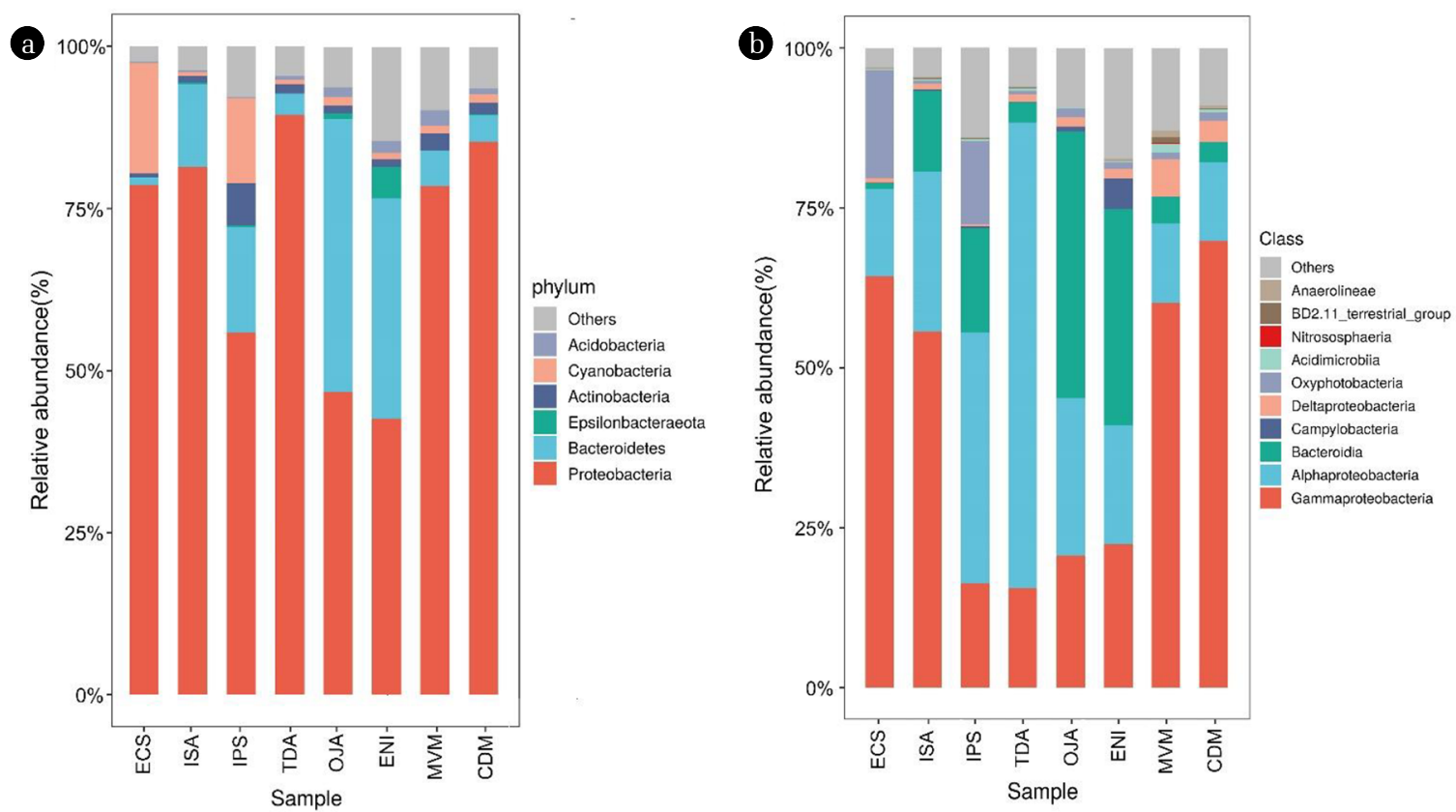

Fig. 5. Relative abundance of microorganisms at the (a) phylum and (b) class levels among the water samples.

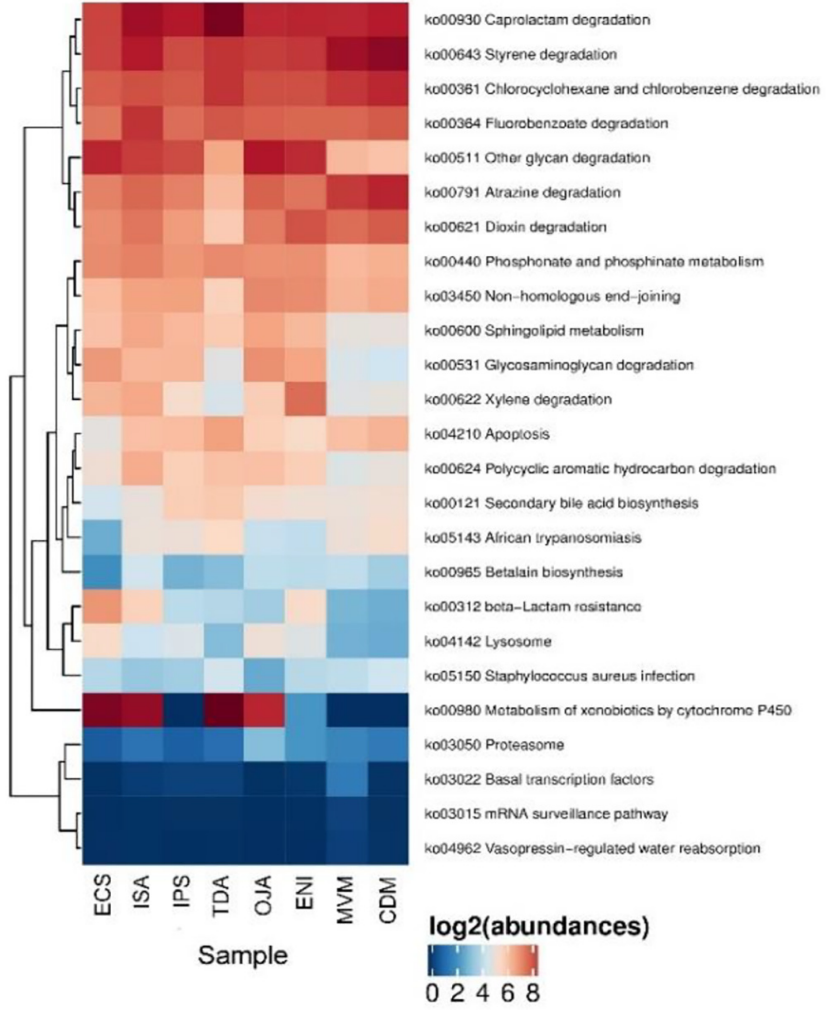

Fig. 6. KEGG pathways associated with predicted gene functions.

the cytochrome P450 metabolic pathway was predicted to be significantly up-regulated in samples for Eichhornia crassipes, lris sibirica, Thalia dealbata, and Oenanthe javanica relative to the abundance in the other samples $(P<0.05)$ (Fig. 6). No significant differences in the predicted genes functions associated with nitrogen and phosphorus metabolism were observed, probably because transformation of nitrogen and phosphorus in an aqueous environment are a complex process in which multiple microorganisms interact to produce different responses. The dominant phylum in each species treatment was Proteobacteria. The dominant class in samples for Eichhornia crassipes, Iris sibirica, Myriophyllum verticillatum, and Ceratophyllum demersum was Gammaproteobacteria. The dominant class in Iris pseudacorus and Thalia dealbata samples was Alphaproteobacteria, and that in Oenanthe javanica and Elodea nuttallii samples was Bacteroidia. Considering the aforementioned differences in the purification capacity of each species treatment, the Alphaproteobacteria and Bacteroidia phyla may contain microorganisms important for degradation of pollutants. In addition, the phylum Bacteroidetes was abundant in all groups; taxa of this phylum play an important role in the degradation of organic matter [19]. Plant allelopathic effects and secreted polyphenols are among the factors responsible for differences in the microbial composition rhizosphere [20].

\section{Discussion}

In water, $\mathrm{NH}_{4}{ }^{+}-\mathrm{N}$ is an essential nutrient that is absorbed by aquatic plants to synthesize proteins and organic nitrogen, which is ultimately converted into biomass. The stems and roots of aquatic plants also provide a suitable substrate and habitat for nitrification and denitrification by microorganisms [21, 22]. The removal of phosphorus is predominantly reliant on absorption by aquatic plants and physicochemical adsorption, whereby microorganisms degrade insoluble phosphorus into soluble phosphate [23], which is directly absorbed by plants. The purification capacity of the 
different species treatments on wastewater in the present study showed that root growth differed among the species and the purification of $\mathrm{NH}_{4}{ }^{+}-\mathrm{N}$, TP, and COD among the different treatments. Thalia dealbata, Oenanthe javanica, and lris pseudacorus produced better-developed root systems and showed superior purification performance, whereas the root systems of Elodea nuttallii and Ceratophyllum demersum developed slowly and were less effective for wastewater purification. Organic matter is hydrolyzed by URE, $\mathrm{AP}$, and $\beta$-GLU to produce inorganic nitrogen, inorganic phosphorus, and glucose, respectively [18]. Plant root metabolites may also promote microbial growth, and enhance enzyme synthesis and activity [14]. In the present study, the activities of URE, AP, and $\beta$-GLU varied significantly with time in the different treatments and increased significantly compared with activities in the control $(P<0.05)$. The patterns of change were generally similar, which is consistent with the results of a previous study of enzyme activities in artificial wetlands [24]. It is evident that the efficacy of extracellular enzymes is consistent in different environments or in different species treatments in the same environment. The above analyses indicated that the magnitude of URE and AP activities was generally consistent with the strength of the plant's ability to remove $\mathrm{NH}_{4}{ }^{+}-\mathrm{N}$ and TP from the water, and was positively correlated with $\mathrm{NH}_{4}{ }^{+}-\mathrm{N}$ and TP removal. However, no significant correlation between $\beta$-GLU activity and COD removal was observed, indicating the factors that influence the capacity for COD purification are complex and require further investigation. A feedback mechanism may exist between enzymes and associated physicochemical factors. In the current study, the rate of increase in URE activity was larger in each treatment at an early stage of the incubation period, probably because $\mathrm{NH}_{4}{ }^{+}-\mathrm{N}$ uptake by plant roots was more rapid in the early stages. Thereafter, the $\mathrm{NH}_{4}{ }^{+} \mathrm{N}$ concentration decreased rapidly, which would trigger a regulatory signal that promoted the increase in URE activity to accelerate the hydrolysis of organic nitrogen. The slow growth in the later stages of the incubation period may be due to decline in the nitrogen source, which slows down its conversion to inorganic nitrogen and the mechanism would thus induce a weakening signal to regulate the balance between organic and inorganic nitrogen. Alkaline phosphatase is a compensatory mechanism for microbially absorbable phosphorus sources in water [25]. The AP activity was positively correlated with TP removal in the present experiment, and thus microorganisms would be induced to produce phosphatase when the inorganic phosphorus concentration was reduced. For this reason, AP is useful as a diagnostic marker for marine phosphorus deficiency [26, 27]. The higher the $\beta$-GLU activity, the more readily biopolymers are hydrolyzed to small organic molecules. The predominant source of glucosidase production in the water column is plankton, which is also the primary source of energy for microorganisms [28, 29]. The optimum $\mathrm{pH}$ for $\beta$-GLU activity in water is in the acidic range, but the enzyme is stable at a $\mathrm{pH}$ exceeding $7.0[30,31]$. The $\mathrm{pH}$ of the water environment in the present experiment ranged between 7 and 8 , thus the effect of $\mathrm{pH}$ on $\beta$-GLU activity was minimal. The present results revealed a significant negative correlation between COD removal and $\beta$-GLU activity in the same treatment $(P<0.05)$, although the relationship differed among the species treatments. The URE, AP, and $\beta$-GLU activities were strongly and positively correlated with the degree of root development in each group of plants. In addition, root secretion and dissolved oxygen enhance enzyme activities [32].

Bacteria constitute the dominant group of microorganisms in water and play an important role in material transformation and energy cycling in a floating island system. The highest microbial diversity and number of species among the present species treatments was observed for Myriophyllum verticillatum, followed by Thalia dealbata and Ceratophyllum demersum. Microbial diversity and species number were not significantly correlated with the activities of URE, AP, and $\beta$-GLU $(P<0.05)$, which indicated to some extent that not all three enzymes originated from bacteria, but also from plants, which is consistent with the results of previous studies [33, 34]. Leaf abscission occurred in submerged plants during the present experiment; leaf decomposition leads to an increase in microorganism abundance, which impacts on the degradation of pollutants [35]. Thus, although microbial diversity was higher for Myriophyllum verticillatum and Ceratophyllum demersum, the effectiveness of the two species for pollutants purification was not outstanding.

The activity of hydrolase varies with temperature [36, 37]. Therefore, further study is needed to determine whether $25^{\circ} \mathrm{C}$ is the optimal temperature and whether the enzyme activity can reach the maximum at this temperature. In addition, the temperature of the water environment is crucial to improve the purification capacity with regard to plant growth, microbe survival, and extracellular enzyme activities.

\section{Conclusions}

This study provides an important theoretical basis for improvement of the effectiveness of aquatic plants, cultured using an artificial floating island system, for purification of pollutants in wastewater. The results demonstrate the relationships among plant species, microorganism diversity and abundance, and extracellular enzyme activity with regard to purification capacity.

During the purification of wastewater by artificial floating islands, an inhibitory relationship is observed between extracellular enzyme activity and $\mathrm{NH}_{4}{ }^{+}-\mathrm{N}$, TP, and COD concentrations. The URE and AP activities are positively correlated with the purification capacity of plants for removal of $\mathrm{NH}_{4}{ }^{+}-\mathrm{N}$ and TP, respectively, whereas $\beta$-GLU activity is not significantly correlated with the purification efficiency of plants for COD removal. The activities of URE, AP, and $\beta$-GLU are significantly and positively correlated with root system development of the plant $(P<0.05)$. Plant roots and microorganisms use water as a medium for secretion of extracellular enzymes, and the roots release substances that enhance enzyme activity.

Microbial diversity in water bodies is strongly influenced by the environment and the associated plant species. The dominant bacterial phylum in each species treatment was Proteobacteria. The relative abundance of Alphaproteobacteria and Bacteroidia was greater than $1 \%$. At the class level, the treatment with Eichhornia crassipes, Iris sibirica, Myriophyllum verticillatum, and Ceratophyllum demersum showed a high abundance of 
Gammaproteobacteria, Alphaproteobacteria were more abundant in the lris pseudacorus and Thalia dealbata treatments, whereas Bacteroidia was more abundant in the Oenanthe javanica and Elodea nuttallii treatments. Each of these classes showed greater than $10 \%$ relative abundance. This variation in microbial species abundance is one possible reason for the influence of enzyme activity and purification efficiency. In addition, microbial metabolism of xenobiotics by cytochrome $\mathrm{P} 450$ was predicted to be up-regulated in the Eichhornia crassipes, Iris sibirica, Thalia dealbata, and Oenanthe javanica treatments.

The present artificial floating island system achieved maximum purification efficiencies of 76.09, 85.87, and 89.10\% for $\mathrm{NH}_{4}{ }^{+}-\mathrm{N}$, $\mathrm{TP}$, and COD by lris pseudacorus, Thalia dealbata, and Oenanthe javanica, respectively. In general, the degree of root development and plant adaptability are important factors affecting the purification capacity of artificial floating island systems. Plant survival and root growth contribute to enhanced extracellular enzyme activity and to the survival and reproduction of systemic microorganisms.

\section{Acknowledgments}

Special thanks to Boao Biotechnology company for technical assistance with molecular work. The authors greatly acknowledge the laboratory facility provided by Shandong Analysis and Test Center. The work was funded by the National Key Research and Development Program of China (2017YFD0801403) and the National Natural Science Foundation of China (41877041; 42077051). We thank Robert McKenzie, PhD, from Liwen Bianji, Edanz Editing China (www.liwenbianji.cn/ac), for editing the English text of a draft of this manuscript.

\section{Authors Contributions}

Q.F.C. (Researcher) did methodology, Resources, Supervision, Writing-review and editing, Funding acquisition. L.L. (Master student) did conceptualization, Formal analysis, Investigation, Methodology, Data curation, Writing-original draft, Writing-review \& editing. Y.F. (Master student) did Investigation, Supervision, Writing - review \& editing. J.Y.L (Master student) did Investigation, Supervision, Writing - review \& editing. Q.L. (Ph. D) did Data curation, Investigation. T.L. (Master student) did Project administration, Supervision.

\section{References}

1. Ware J, Callaway R. Public perception of coastal habitat loss and habitat creation using artificial floating islands in the UK. Plos One. 2019;14:e224424.

2. Kong L, Wang L, Wang Q, Mei R, Yang Y. Study on new artificial floating island removing pollutants. Environ. Sci. Pollut. Res. 2019;26:1-11.

3. Guo L, Tian Y, He YH, Zheng Y, Chen LJ, Li, QQ. Study on the purification effect of aeration-enhanced horizontal subsurface-flow constructed wetland on polluted urban river water. Environ. Sci. Pollut. Res. 2019;26:12867-12871.

4. Hubbard RK, Anderson WF, Newton GL, Ruter JM, Wilson JP. Plant growth and elemental uptake by floating vegetation on a single-stage swine wastewater lagoon. T ASABE. 2011;54:837-845.

5. Kong L, Wang L, Wang Q, Mei R, Yang Y. Study on new artificial floating island removing pollutants. Environ. Sci. Pollut. Res. 2019;26:1-11.

6. Sun L, Liu Y, Jin H. Nitrogen removal from polluted river by enhanced floating bed grown canna. Ecol. Eng. 2009;35: 135-140.

7. Sooknah RD, Wilkie AC. Nutrient removal by floating aquatic macrophytes cultured in anaerobically digested flushed dairy manure wastewater. Ecol. Eng. 2004;22:27-42.

8. Dai X, Zhong R, Zhang X, Zhang J, Luan L. Comparative study on nitrogen and phosphorus removal efficiency of urban inland water plants. Inner. Mongolia. Environ. Sci. 2018;30:110.

9. Zhang Z, Liu J, Zhang Z, Zhang M. Comparison of Removal efficiency of nitrogen and phosphorus by artificial floating islands with different plants. Wetland ence. 2018;2:273-278.

10. Sheng Z, Hosomi M. Nitrogen transformations and balance in a constructed wetland for nutrient-polluted river water treatment using forage rice in Japan. Ecol. Eng. 2008;32:147-155.

11. Chang $\mathrm{YH}, \mathrm{Ku} \mathrm{CR}$, Lu HL. Effects of aquatic ecological indicators of sustainable green energy landscape facilities. Ecol. Eng. 2014;71:144-153.

12. Zhou S, Hosomi M, Nitrogen transformations and balance in a constructed wetland for nutrient-polluted river water treatment using forage rice in Japan. Ecol. Eng. 2007;32:147-155.

13. Desorbo CR, Fair J, Taylor K, Hanson W, Jr J. Guidelines for Constructing and Deploying Common Loon Nesting Rafts. Northeastern. Nat. 2015;15:75-86.

14. Gonnelli M, Vestri S, Santinelli C. Chromophoric dissolved organic matter and microbial enzymatic activity. A biophysical approach to understand the marine carbon cycle. Biophys. Chem. 2013;182:79-85.

15. Steen $\mathrm{AD}$, Arnosti C. Long lifetimes of $\beta$-glucosidase, leucine aminopeptidase, and phosphatase in Arctic seawater. Mar. Chem. 2011;123:127-132.

16. Kong L, Wang YB, Zhao LN, Chen ZH. Enzyme and root activities in surface-flow constructed wetlands. Chemosphere 2009;76: 601-608.

17. Zhao X. Isolation and identification of inter-rooted microorganisms from several wetland plants and their effluent purification effect dissertation]. Ocean University of China; 2012.

18. Yang K, Metcalf WW. A new activity for an old enzyme: Escherichia coli bacterial alkaline phosphatase is a phosphite-dependent hydrogenase. P. Natl. Acad. Sci. Usa. 2004;101:7919-7924.

19. Zhang L, Zhang S, Lv X, Zheng Q, Zhang Z, Yan L. Dissolved organic matter release in overlying water and bacterial community shifts in biofilm during the decomposition of myriophyllum verticillatum. Sci. Total Environ. 2018;633:929-937.

20. Pang S, Zhang S, Yang X, et al. Characterization of bacterial community in biofilm and sediments of wetlands dominated 
by aquatic macrophytes. Ecol. Eng. 2016;9:242-250.

21. Miyoko W, Kaoru A, Tomoko Y, Yasuyuki F. Tolerance of anammox reactor packed with zeolite to partial supply of nitrite or ammonium using purified livestock wastewater. Environ. Technol. 2018;41:1411-1418.

22. Zuo XJ, Zhang HS, Yu JH. Microbial diversity for the improvement of nitrogen removal in stormwater bioretention cells with three aquatic plants. Chemosphere 2020;244:12526

23. Brown MT, Treavor B, Sindelar RJ, Sam A, Amar P, Sherry BW. A floating island treatment system for the removal of phosphorus from surface waters. Engineering 2018;4:597-609.

24. Kumar S, Nand S, Dubey D, Pratap B, Dutta V. Variation in extracellular enzyme activities and their influence on the performance of surface-flow constructed wetland microcosms (CWMs). Chemosphere 2020;251:126377.

25. Rose C, Axler RP. Uses of alkaline phosphatase activity in evaluating phytoplankton community phosphorus deficiency. Hydrobiologia. 1997;361:145-156.

26. Allan D, Cembella NJ, Antia PJ, Harrison G. The Utilization of Inorganic and Organic Phosphorous Compounds as Nutrients by Eukaryotic Microalgae: A Multidisciplinary Perspective: Part 2. Crit. Rev. Microbiol. 1984;11:13-81.

27. Lin X, Zhang H, Cui Y, Lin S. High Sequence Variability, Diverse subcellular localizations, and ecological implications of alkaline phosphatase in dinoflagellates and other eukaryotic phytoplankton. Front. Microbiol. 2012;3:235.

28. Ryszard JC. Characterization and significance of $\beta$-glucosidase activity in lake water. Limnol. Oceanogr. 1989;34(4):660-672.

29. Turner BL, Hopkins DW, Haygarth PM, Ostle NJ.
BETA-Glucosidase activity in pasture soils. Appl. Soil Ecol. 2002;20(2):157-162.

30. Chen QX, Shi Y, Zhang Z, Huang JS, Zhuang ZL. Kinetics of Inactivation of $\beta$-glucosidase from Ampullarium crossean in Urea Solutions. J. Xiamen University(Nat Sci). 2000;39:102.

31. Hua L, Li G. Research advance on Methods of determining $\beta$-Glucosidase Activity. J. Food Biochem. 2007;2:107-114.

32. Rosa R, Isabel C. Enzymatic activity in the rhizosphere of spartina maritima: potential contribution for phytoremediation of metals. Mar. Environ. Res. 2008;65:77-84.

33. Salerno M, Stoecker DK. Ectocellular glucosidase and peptidase activity of the mixotrophic dinoflagellate prorocentrum minimum (dinophyceae). J. Phy. 2009;45:34-45.

34. Ou L, Huang B, Hong H, Qi Y, Lu S. Comparative alkaline phosphatase characteristics of the algal bloom dinoflagellates Prorocentrum donghaiense and Alexandrium catenella, and the diatom Skeletonema costatum. J. Phy. 2010;46:260-265.

35. Mille-Lindblom C, Tranvik LJ. Antagonism between Bacteria and Fungi on Decomposing Aquatic Plant Litter. Microbial. Ecology. 2003;45:173-182.

36. Kim HW, Nam JY, Kang ST, Kim DH, Jung KW, Shin HS. Hydrolytic activities of extracellular enzymes in thermophilic and mesophilic anaerobic sequencing-batch reactors treating organic fractions of municipal solid wastes. Bioresour. Technol. 2012;110:130-134.

37. Yang Q, Luo K, Li XM, et al. Enhanced efficiency of biological excess sludge hydrolysis under anaerobic digestion by additional enzymes. Bioresour. Technol. 2010;101:2924-2930. 